\title{
Managing Knowledge across Boundaries in Healthcare when Innovation is Desired
}

\author{
Mats Edenius*
}

Department of Informatics and Media

Uppsala University

PO Box 513, SE-751 20 Uppsala, Sweden

E-mail: mats.edenius@im.uu.se

*Corresponding author

\section{Christina Keller}

Department of Informatics and Media, Uppsala University, and Department of Informatics, Jönköping International Business School PO Box 1026, SE-551 11 Jönköping, Sweden

E-mail: christina.keller@ihh.hj.se

\section{Staffan Lindblad}

Medical Management Centre

Karolinska Institutet

SE-171 77 Stockholm, Sweden

E-mail: staffan.lindblad@ki.se

\begin{abstract}
The purpose of this study is to explore how knowledge can be managed across boundaries when implementing innovations in the healthcare sector is desired, in this specific case a healthcare quality register. The research is based on a qualitative, case study approach and comprises methodologies such as semi-structured interviews and document analysis. The findings of this study describe knowledge transferred across boundaries on a syntactic, semantic, and pragmatic level. On the syntactic level, knowledge of the innovation was transferred by training sessions for healthcare staff and through information to patients. On the semantic level, knowledge was transferred by knowledge brokering in the professional community of rheumatologists, and by creating collective stories and encouraging rheumatologists to "try" the innovation to find added value. On the pragmatic level, there were explicit conflicts of interest between physicians and healthcare authorities, as well as resistance from some rheumatologists to share knowledge of patients and treatment. The paper is concluded with implications for innovation practice in healthcare drawn from the study and ends with remarks about challenges ahead.
\end{abstract}

Keywords: Knowledge Management, Knowledge Boundaries, Healthcare, Innovation, Healthcare Quality Register.

Biographical notes: Mats Edenius holds a $\mathrm{PhD}$ in Business Administration and is Professor of Information Systems at Uppsala University, Department of Informatics and Media, Sweden. His research interests lie within the areas of information technology, knowledge and management. 


\begin{abstract}
Christina Keller holds a PhD in Information Systems and works as an Assistant Professor and Researcher at Jönköping International Business School and Uppsala University, Sweden. Her research interests include information technology innovations in healthcare, online learning, and design science research.

Staffan Lindblad holds a MD and a PhD in Rheumatology, and works as an Associate Professor at Medical Management Centre, Karolinska Institutet and at Karolinska University Hospital, Sweden. His research interests include quality improvement in rheumatology care.
\end{abstract}

\title{
1. Introduction
}

The increase in patient expectations, availability of new treatments from pre-clinical research, increased demands on professional knowledge, as well as economic constraints all challenge the capability of the healthcare system to match the increasing gap between what is possible, appropriate, safe, and cost-effective and what happens in practice when healthcare is delivered. To cope with this gap, healthcare organizations need continuous renewal to transform the entire system to deliver better patient outcomes, better professional development and better system performance. Hence, the healthcare sector must confront the challenge to organize and manage innovation on a continuous basis. The healthcare sector from this stance is not an exception compared to other organizations in society (Tushman and O'really, 1997; Brown and Eisenhardt, 1997; Bosa, 2008).

However, innovation never takes place in a vacuum. Most innovations happen at the boundaries between disciplines or specializations (Leonard-Barton, 1995). It is novel or incremental changes that induce processes that might be addressed as an innovation. This underscores two major challenges: we need to capture and illuminate knowledge processes between people or groups of people with different knowledge, perspectives, and/or specializations in order to manage innovations. Furthermore, the characteristics of knowledge that drive innovations within a function may also hinder innovation, because knowledge is both a source of, and a barrier towards, innovation (Brown and Duguid, 1998; Carlile, 2002).

Innovation is an elusive concept. Innovations can be new ideas, new technologies, new artefacts, and new ways of doing things (cf. Rogers, 1995). It can also be a recombination of old ideas etc. that challenges the present order (van de Ven, 1986). It refers not just to an outcome (a new idea for example), but also to the process, i.e. how the new ideas emerge and how they are technologically supported (Gupta et al., 2007). Furthermore, not all ideas, practices or objects are recognized as innovations. Innovation has to do with things that are perceived or defined as new by the relevant unit of adoption (Rogers, 1995; Zaltman et al.; 1973), i.e. it is the perception of newness that counts, rather than whether the idea or object is new to the outside world.

Much research on innovation has been conducted from the perspective of the individual in order to create, produce or inspire innovations (Mumford, 2000; McAdam and McClelland, 2002). Research studies taking an interest in the basic conditions for implementation of innovations in organizations are more scarce (Jong and Hartog, 2007; King and Andersson, 2002). This also holds true for research about innovation in the healthcare sector (Bosa, 2008; Thorne, 2002; cf. Research on Innovation, 2010). 
This article addresses this gap by focusing on an innovation in the healthcare sector; a medical quality register, and discusses the basic conditions for this register to become a successful innovation. A register, working as an information system, may not be seen as "something new" at first sight. However, as we will show, the quality register can be seen both as a new idea, and a product. It interferes with institutionalized working and treatment processes, and in so doing changes physicians' every day work and patients engagement in the treatment processes. Acknowledging that an innovation ought to be seen in a further context and recognizing that innovation happens at the boundaries between different people, with different backgrounds, perspectives, and competencies, this paper seeks to highlight the challenges the healthcare sector face when innovation is desired and how these challenges might be managed. This is the aim that motivates the inquiry presented in this article. The argumentation will be buttressed by central ideas from Carlile's (2002; 2004) integrative framework for managing knowledge across boundaries and supported by empirical material represented by a case study of a healthcare innovation; a Swedish quality register for rheumatoid arthritis care.

The article is organised in the following way: first, our theoretical framework, the concept of knowledge boundaries, is presented; second, the methodology of the study is described; third, the empirical findings of the study are presented and discussed. Finally, conclusions and implications for practice are put forward.

\section{Theoretical framework}

Healthcare is in good company in being slow to use new knowledge. Diffusion of innovation is, after all, a challenge in many human enterprises. However, much more attention needs to be paid to the underlying capacity of healthcare organizations to absorb new knowledge (Berwick, 2003; Fitzgerald et al., 2002). With this spirit in mind, we follow the vein that to sustain the pace of innovation, organizations need to improve their ability to produce, integrate and recombine knowledge (e.g. Verona et al., 2006; Teece et al., 1997).

\subsection{Knowledge boundaries}

Dorothy Leonard-Barton's (1995) statement that most innovations happen at the boundaries between disciplines or specializations tells us, as Carlile (2004) argues, that working across boundaries is not only the key ingredient of competitive advantage and improvement, but illuminates why innovation is so hard to maintain and implement. The contemporary organizational literature on knowledge sharing across boundaries has three main perspectives (Brown and Duguid, 1998; Carlile, 2002; Kellog et al., 2006). First is the information processing perspective, where organizational members are seen as to be instrumental in their knowledge sharing behaviours, albeit within the limits of their bounded rationality (Simon, 1982). Breakdowns and difficulties in knowledge sharing arise from incompatible codes, lack of information, routines and/or protocols (Kellog et al., 2006) - a problem characterized by Carlile (2004) as one of syntax. The second perspective recognizes the limitations of a common syntax or language present and stresses the importance of recognizing that interpretative differences often exist. To understand and be able to manage innovation processes, we also have to put focus on cultural and softer aspects of boundary spanning than in the information processing perspective - what Carlile (2004) refers to as a problem of semantics. However, differences in meanings, assumptions, and contexts are far from easy to tackle. Even if we can find many different ways to share knowledge, like the use of a shared language, 
shared meanings (Smirch, 1983) or collective stories (Boland and Tenkasi, 1995), there are many situations where dependencies make it hard to share knowledge because too much is at stake for the actors. Hence, the third perspective puts focus on political and power relations, as knowledge and knowledge sharing is seen as inseparable from individuals' interests and actions in specific contexts. People are reluctant to change their hard-won outcomes, because it is costly and difficult to achieve knowledge and skills..."it requires investment on time and relationship building, as well as compromises ..." (Kellog et al., 2006, p. 24). This third perspective is characterized by Carlile (Ibid) as pragmatic. We put forward the suggestion that successful innovations in the healthcare sector are dependent on knowledge boundary management, by which knowledge can be transferred, translated and transformed among the actors in the social system where the innovation takes place and that the innovation as such cannot be separated from these processes.

According to Carlile's $(2002,2004)$ framework, knowledge on the syntactic level might be fairly well-known to the actors. When the common lexicon (language) sufficiently specifies the differences and dependencies among actors, the boundary is experienced as unproblematic and the focus of boundary management is "simply" to transfer knowledge. The translation from a syntactic to a semantic boundary occurs when the degree of novelty of an innovation is increased, and makes knowledge differences and dependencies unclear or the meaning ambiguous. Finally, the transition from a semantic to a pragmatic boundary arises when the further increasing novelty of the innovation results in the emergence of different interests among actors in the social system (Carlile, 2004). The framework is depicted in figure 1.

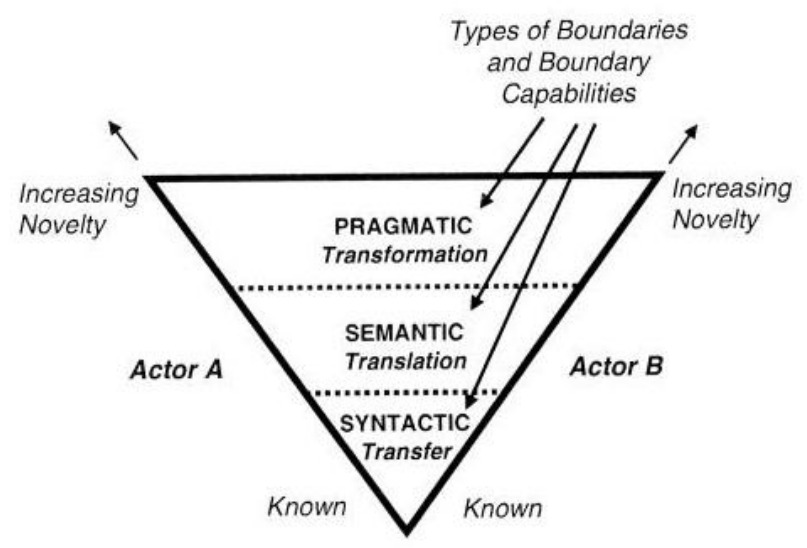

Figure 1. An integrated/3-T framework for managing knowledge across boundaries (Carlile 2004).

This perspective underscores three challenges when innovation is desired. We need to increase the capacity to process "more" information, so context-specific aspects of creating knowledge and transferring knowledge must be taken into consideration, like creating new agreements that require practical and political effort. Within such a pragmatic approach we argue that a common lexicon is necessary, but not always sufficient to share and assess knowledge across boundaries. Furthermore, to create common meaning to share and assess knowledge often requires creating new agreements, which in turn requires significant practical and political effort (see Carlile, 2004, p. 560). 
Our notion is that this perspective constitutes an analytical framework to better understand the challenges and potential, not only as actors work across domains when service innovations is desired, but also how service innovations might be successfully implemented and managed in healthcare organizations. Approaches to sharing and assessing domain-specific knowledge across boundaries are described schematically in table 1 .

Table 1. An abbreviated comparative summary of approaches to sharing and assessing domain-specific knowledge across boundaries (see Carlile, 2004).

\begin{tabular}{|c|c|c|c|}
\hline & $\begin{array}{l}\text { Syntactic boundary: } \\
\text { A transfer or } \\
\text { information- } \\
\text { processing approach }\end{array}$ & $\begin{array}{l}\text { Semantic boundary: } \\
\text { A translation or } \\
\text { interpretive } \\
\text { approach }\end{array}$ & $\begin{array}{l}\text { Pragmatic boundary: } \\
\text { A transformation or a } \\
\text { political approach }\end{array}$ \\
\hline $\begin{array}{l}\text { Circum- } \\
\text { stances }\end{array}$ & $\begin{array}{l}\text { Differences and } \\
\text { dependencies } \\
\text { between actors are } \\
\text { known. A common } \\
\text { lexicon is developed } \\
\text { that is sufficient to } \\
\text { share and assess } \\
\text { knowledge at a } \\
\text { boundary. }\end{array}$ & $\begin{array}{l}\text { Novelty generates } \\
\text { some differences and } \\
\text { dependencies that are } \\
\text { unclear - different } \\
\text { interpretations exist. } \\
\text { Common meanings } \\
\text { are developed to } \\
\text { create shared } \\
\text { meanings and provide } \\
\text { an adequate means of } \\
\text { sharing and assessing } \\
\text { knowledge at a } \\
\text { boundary. }\end{array}$ & $\begin{array}{l}\text { Novelty generates } \\
\text { different interests } \\
\text { between actors that } \\
\text { impede their ability to } \\
\text { share and assess } \\
\text { knowledge. Common } \\
\text { interests are developed to } \\
\text { transform knowledge and } \\
\text { interests and provide an } \\
\text { adequate means of } \\
\text { sharing and assessing } \\
\text { knowledge at a } \\
\text { boundary. }\end{array}$ \\
\hline Challenges & $\begin{array}{l}\text { A common lexicon is } \\
\text { necessary but not } \\
\text { always sufficient to } \\
\text { share and assess } \\
\text { knowledge across a } \\
\text { boundary. }\end{array}$ & $\begin{array}{l}\text { To create common } \\
\text { meanings to share } \\
\text { and assess knowledge } \\
\text { often requires } \\
\text { creating new } \\
\text { agreements. }\end{array}$ & $\begin{array}{l}\text { To create common } \\
\text { interests to share and } \\
\text { assess knowledge } \\
\text { requires significant } \\
\text { practical and political } \\
\text { effort. }\end{array}$ \\
\hline
\end{tabular}

\section{Methodology}

A single in-depth case study was adopted to obtain rich and naturalistic data. This approach is suitable, given the explorative character of the study and that the key purpose of the study is to highlight a construct, by showing its operation in an ongoing social context (cf. Yin 2009). 
The perspective employed in this article is based upon what Orlikowski (1992; 2000) has coined as "a practice lens for understanding technology use". Employing such a practice draws attention to emergent structures enacted in practice when a technique is used in different milieus in recurrent ways in everyday situated activities. This study is in line with what has been called "practice turn" in social theory (Lave and Wenger, 1991; Orlikowski, 1992), emphasizing a less abstracted and more common sense notion of reality. This practice lens approach ameliorates appreciation of the lived complexities of human organization, where the social is a field of embodied, materially interwoven practices, centrally organized around shared practical understandings where the actions are.

Interviews and document analysis constituted the modes of the investigation. The empirical approach is closely linked to what has been called making ethnographic interviews, where interviews (sessions) are conducted in work environments, where people can act more naturally, and where the researcher can take into account and explore surrounding settings (Barley \& Kunda, 2004; Spradley, 1979; Taylor \& Bogdan, 1998). The case study methodology is frequently criticised for being dependent on a single case, which renders it incapable of providing a generalising conclusion. However, Yin (2009) had extended and complemented this argument by proposing that there is a difference between analytical generalisation and statistical generalisation. In analytical generalisation, previously developed theory (Carlile's analytical framework in our case) is used as a template to compare empirical results of the case study (Yin, 2009, p.15). This study is inspired by this way of regarding generalisation and is centred on a more intuitive, empirically grounded generalisation that sees a harmonious relationship between the reader's experiences and the case study itself (Stake, 1995). From such a standpoint, a case study is both the process of learning about the case and the product of our learning. The intention of our case study has not primarily been to solve the problem at stake, but to work with the situation that presents itself in each case, to clarify and gain a better understanding (cf. Stake, 1995; Hanson, 1958). The approach might be said to be abductive (Hanson, 1958). The abductive approach encapsulates this kind of uncertainty that is present in this research approach. In line with such an approach, the empirical material speaks as if it solves the question at stake, equivalent to the propositions we make up. The explorative approach of this paper follows the vein of Charles Sanders Peirce (cf. Tsoukas, 1989) who suggests that making a reasonable guess is the only way of getting closer to attaining new and fruitful knowledge.

A series of interview questions were developed from this approach. Twenty interviews were performed with implementers, clinical managers and rheumatologists from six Swedish hospitals in four county councils. Each person was contacted by phone or email to set up a time to conduct the interview in their offices. Each in situ interview took from 30 to 100 minutes. The survey questions were used as a guide for the conversation, rather than as a strict question-and-answer tool. In this way, the interviewers were able to structure the conversation in a way that obtained the most relevant information about how the respondent's perceived the innovation.

Each interview was recorded and each of these was later transcribed verbatim. In addition, notes were taken throughout each interview. During the interview with the various representatives, the discussions were substantially richer in content than the following text and summary depict. Different data were identified and put into different sub-themes of classified patterns in line with Constas' (1992) note that the interpretative approach should be considered as a "distinct point of origination" related to our 
theoretical framework. Inspired by a critical incident approach, several different "distinct points of origination" were located. We strategically looked for collecting direct observations that seem to have critical significance on the innovation process. These observations were then kept track of as incidents, which were then used as a template for the empirical material. Parallel with the empirical fieldwork we also started to conduct a thematic analysis (cf. Taylor and Bogdan, 1998) linked to critical incidents technique (CIT) (Gremler, 2004). The CIT method, in general, could be said to represent a compromise between the structure of standardized quantitative surveys and the descriptive richness of open ended qualitative studies. The CIT method requires respondents to report their view based on direct observation of specific incidents. Because the CIT requires respondents to focus on specific events, the process captures some overt behavioral richness which might be lacking in studies with other kinds of methods.

\section{The innovation at stake}

Although patient work is the core of health service, corresponding information systems have not been developed for working with patients. The traditional patient record systems have not facilitated compilation and analysis of data required for quality improvement, as they are essentially treated like note pads supporting the treatment of individual patients by individual physicians. (Swedish Association of Local Authorities and Regions, 2007): "The National Quality Registries have been developed to fill the gap left by the lack of primary monitoring systems. The quality registries collect information on individual patient's problems, interventions, and outcomes of interventions in a way that allows the data to be compiled for all patients and analyzed at the unit level." (p. 10). Although most quality registers are of recent date, national registers have existed in Sweden since the 1970s, the first register being the Register for Knee Arthroplasty, which began as a research project in 1975 (Garpenby \& Carlsson, 1994). The development of national quality registers have been decentralized in its nature, mainly accomplished by professional communities themselves. Practitioners having the greatest use of the data also have been responsible for the development of the registers and their content, and the databases are spread among clinical departments nationally (Swedish Association of Local Authorities and Regions, 2009).

The effects of treatment on individual patients could be monitored, and data is aggregated to show treatment outcomes based on groups of patients. The treatment outcomes could be compared with the national average or with treatment outcomes of other clinics, thus providing benchmarking data. Furthermore, the design of guidelines for medical treatment on a national level could be based on information obtained by means of quality register data. In 2009, 69 quality registers were established in Sweden, comprising e.g. respiratory diseases, diseases of childhood and adolescence, circulatory diseases, endocrine diseases, gastrointestinal disorders, musculoskeletal disorders and diseases of the nervous system (Swedish Association of Local Authorities and Regions, 2009).

The primary goal of quality registers is to improve knowledge about different medical interventions and thus improve quality of treatment in healthcare. A register may be either disease-oriented or method-oriented. A disease-oriented register focuses on the diagnosis of the patient and records all relevant treatment, while method-oriented registers are based on the recording of procedures, such as certain kinds of surgery. Different registers have different objectives, depending on e.g. medical specialty, but 
some objectives are common, such as to describe variations in the utilization of different methods, to describe differences in treatment outcomes among different departments, to monitor and assess the effectiveness of different methods over time, and to include the patient's experience of health changes and quality of life over the course of time (Garpenby \& Carlsson, 1994).

\subsection{The Swedish rheumatology quality register}

Discussion of a quality register in rheumatoid arthritis started in 1993 in the professional community of Swedish rheumatologists. In the end of the 1980s, new effective treatment against rheumatoid arthritis had been introduced along with the insight that rheumatoid arthritis should be treated in the very early stages of the disease. With the introduction of the new treatment, a growing interest could be discerned among rheumatologists in evaluating treatment outcomes. The idea of the Swedish quality register of rheumatoid arthritis evolved at the 1993 annual conference for Swedish physicians. It was inspired by the Better Anti-Rheumatic Pharmacotherapy (BARFOT) study group. In 1995, the quality register was launched, and patient and treatment data were registered on paperbased forms, which the patient was asked to complete before the medical consultation. Data from the paper-based forms were entered into the quality register after the medical consultation. We refer to this kind of register use as reactive. In 2001, a web-based user interface was introduced, which enabled the patient to enter patient data before the consultation and be entered by the physician and patient together during the medical consultation; a proactive use of the register. In 2006, the web-based user interface began to spread among Swedish rheumatology clinics. In the county council of Dalarna, rheumatoid arthritis patients are able to register their disease activity from a web-based user interface independent of place. All other patients register their data on a computer placed in the waiting-room at the hospital. In 2009, 52 rheumatology clinics participated in the register. In some county councils all rheumatology patients were included in the register. Treatment data of 33049 patients were registered. The patient data entered into the register comprises e.g. treatment, findings of laboratory tests, self-assessed patient evaluations of general pain, tiredness, and swelling and tenderness of 28 index joints. When the patient has entered data, a summary of disease activity is created by the register, labeled as DAS28 (Disease Activity Score). The DAS28 index serves as a point of reference from which treatment outcomes are evaluated (Keller et al., 2009). When the patient has entered data, a summary of disease activity can be printed and the patient can bring the summary to the medical consultation. The summary gives a comprehensive overview of disease activity and treatment over time. The measure of DAS28 is colourcoded to indicate whether the disease activity is high (red), moderate (yellow), low (green) or non-existent (white). The summary of disease activity is presented in figure 2 . 


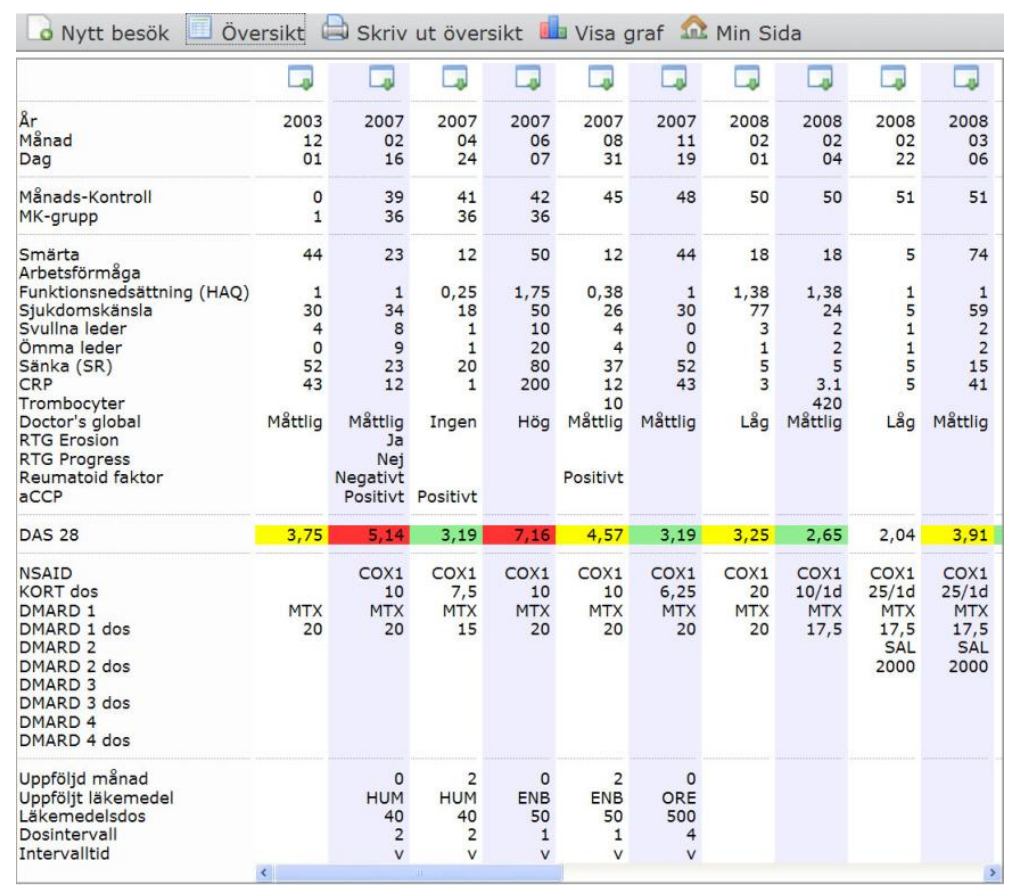

Figure 2. Summary of disease activity.

The summary of disease activity, whether on paper or on the computer screen, can be used as a common decision-support system in the physician-patient dialogue. Together with the physical examination of the patient by the physician, the summary will form the basis of the decision on further treatment: "My physician goes through the categories of the register when we talk about my disease and "tick them off". It seems to me that using the register makes our dialogue more complete and comprehensible." (patient). "The patient registers data, which I process and we reach a common decision which is shown in a summary showing both hard and soft data." (clinical manager).

At the end of the consultation, a new summary bringing together the input from both patient and physician is compiled. The summary gives a comprehensive and "easyto-read" view of the health status of the patient. Some physicians use the summary of disease activity as a source of information before the next medical consultation: "To read the summary before the medical consultation saves ten minutes, which I can use to examine the patient, instead of trying to read e.g. 750 pages of patient records." (clinical manager). Furthermore, researchers and physicians in clinical practice before 1993 describe the difference before and after the introduction of the quality register as: "You get an overview of the disease [by means of the register], and that is difficult to achieve by only unstructured, longitudinal notes. You get structured and quantified data, which makes it easier to evaluate the actual health status of the patient." (researcher).

Rheumatoid arthritis is a slowly progressing chronic disease and before the 1990s it was quite common that the medical records stated that the patient's health status was stable over ten years, when actually it was gradually worsening to the point where the patient was completely disabled. The gradual deterioration caused by the disease, and the effect of therapies are more clearly discernable by means of the register. 
Biological drugs and their side effects are given particular attention in the register. Since 2001, patients and their physicians can use internet services for proactive decision support during the medical consultation. In addition to the immediate feedback during the consultation, all users have access to an internet service that makes the data available directly after entry. Diagrams are updated every night, showing information about patient groups and diagrams comparing treatment data of counties and regions as well as nationally (Swedish Association of Local Authorities and Regions, 2009).

The basic assumption underpinning the implementation and register is that the quality improvement process is most effective in the interaction between the patient and the physician. The interaction is facilitated by using the register online at increasingly more medical consultations. The ongoing follow-up of the disease activity by the patient health status index has led to better results of treatment every year since the register started. The register has also played an important role in the dissemination of biological therapies in rheumatoid arthritis care, enabling them to be used efficiently and equitably throughout the country (Swedish Association of Local Authorities and Regions, 2009; Keller et al., 2009).

\section{Findings: What made the innovation possible?}

\subsection{Transferring knowledge boundaries on a syntactic level}

Healthcare work routines are knowledge intensive and the unwillingness to change work routines without good reason seems to be a significant factor in rejecting the innovation: "After all, physicians have created their own personal "flow" of how to interview and examine the patient and make our conclusions at the end of the consultation. The thing is to make it [the use of the quality register] a natural part of the medical consultation." (clinical manager). Also patients have their own routines in connection to the medical consultation, which have to be considered: "Some patients are constantly on the go. They insert coins in the parking meter and don't think that they have time to be at the clinic 20 to 30 minutes earlier [to entry data into the patient interface of the register]..." (clinical manager).

From 1993 until 1995 the implementation process focused on negotiations and decisions among the Swedish rheumatology community about what knowledge to include in the quality register and the actual creation of the computer-based register. From the launch of the computer-based register in 1995, the intention of the champion implementer(s) has been to spread the innovation among colleagues through the main communications channels such as professional networks, associations and meetings. This is in no way a top-down implementation of an innovation. Nor is it a bottom-up implementation, but an implementation process between peers. The strategy of the implementer(s) has been one of presenting win-win situations provided by the use of the register and a constant offer to try the innovation in order to find out if its use will bring any advantages to the individual rheumatologist: "You have to be diplomatic and in some way be a friend of most of your colleagues... You cannot force colleagues to accept and drive change. You have to listen to them, and then, with the respect that you command, put forward the reasons - and above all - the added value that the innovation can bring to the individual." (champion implementer).

On the syntactic level, the first years of the innovation time-line was also spent on creating a common syntax of disease measurements, and negotiations about the user interface and what statistical reports were to be created from the register. To manage this 
knowledge boundary required the champion implementers to be active knowledge brokers among colleagues. When designing and using quality registers, it is common that - in line with a syntactical approach - physicians want to include as much measures and variables as possible about the disease. However, it is important that the numbers of variables registered do not exceed that which physicians and patients have time and energy to fill in. The trade-off between number of variables and time spent on data registration is a challenge which is essential to manage in order to make physicians and patients accept and use the quality register.

Knowledge of the contents and features of the register was also transferred by organized training sessions offered to physicians and nurses by champion implementers. The training sessions were also sources for input on necessary changes of interface and reports. Perceived flaws in interface and reports of the register were challenges which had to be handled in this context. Another means of knowledge transfer on the syntactic level is the focus on information to patients using the internet-based interface to report selfassessed evaluations of general pain, tiredness, and swelling and tenderness of index. For this purpose, one specific dedicated person is employed as healthcare designer. Rheumatology patients interest groups and information folders distributed among rheumatology patients were used to spread information about the internet-based interface.

\subsection{Translating knowledge on a semantic level}

On the semantic level common meanings needed to be developed about the purposes of using the register in clinical practice and research. This was accomplished by encouraging rheumatologists to "try" the innovation to experience what added value could be created in clinical practice and research. To enable physicians to "make their own interpretation" of how the register could be used and what added value it could bring has been a successful strategy, as physicians perceive the decision to use the register as their own, not as something imposed from outside.

According to Montgomery (2006), the practice of medicine is characterized by a combination of a body of scientific knowledge and a collection of well-practiced skills. Clinical judgment is defined as the practical reasoning that enables physicians to fit their knowledge and experience to the circumstances of each patient. There is evidence from the interviews that the characteristics of the physician-patient dialogue are changed by the use of the quality register. As one rheumatologist describes it: "It is like having a third person in the room... But it feels secure and comfortable, as the computer presents facts and not guesses or beliefs." There is also evidence of tacit knowledge of patients and physicians being confirmed or made explicit by the register (Nonaka, 1994), as e.g. a vague perception of decreasing health status of the patient could be confirmed as an increase of disease activity measured and compiled by the system: "The patient tells me that he or she doesn't feel very well. Then I take a look at the results from the laboratory tests or the [DAS28] index, and I can confirm that the patient's health status has decreased. It is a fact and not just a vague perception or whimpering." (rheumatologist). There was also some evidence that the compliance of patients to recommended treatment has increased with the use of the quality register. It is difficult for patients to lie about taking or not taking their medicine when they are asked directly in front of a computer screen and their response is registered. When it comes to knowledge translation on the semantic level, the biggest challenges are to change the work routines of physicians and make them accept "a third person" (the register) in the physician - patient relationship. 


\subsection{Transforming knowledge on a pragmatic level}

On the pragmatic level, the creation of the register evoked conflicts of interest among rheumatologists, county council managements and healthcare authorities, such as The National Board of Health and Welfare and Swedish Association of Local Authorities and Regions. A number of rheumatologists opposed the register as they did not want to be controlled by authorities - as they perceived it (cf. Jacobs et al., 2004). The solution to this conflict was to encourage use of the register to improve the health status of patients instead of as a means of control. The champion implementers took on the strategy of stressing the shared value and common interest of physicians and authorities of healthier patients given the right treatment. Furthermore, as the newly developed biological drugs used in treating rheumatoid arthritis are very expensive, the knowledge of treatment outcomes has become an indispensable means of argument of physicians towards politicians of the county councils in proving that the treatment is needed and that the increase in costs brings an improved health status of patients: "By means of the register we can tell politicians that a certain number of patients need the biological drugs... without the register we wouldn't have stood a chance." (rheumatologist). "We have to use the quality register. It's our only means of quality improvement." (clinical manager).

Moreover, there were some conflicts initially according to where in Sweden the quality register should be based and, hence, the research on the data of the register should be accomplished: "There was a considerable amount of resistance emanating from different universities and where this research should be done. And there is still some opposition towards "those people from Stockholm", who would not only manage the register but also benefit from it." (rheumatology professor).

In this case the quality register could act as a boundary object bridging the gap between fundamentally different interest groups in helping them understand that their goals of increased patient health status are more identical than they initially think. Another way to put it is to say that the register helped them to overcome their defence of their professional jurisdiction from external intrusion and not use an innovative technology as part of a defensive strategy (see for example Bosa, 2008; Thorne, 2002). That made it easier for the rheumatologists to invest in new knowledge about the register and how it worked. It became so clear for many of the physicians that the register could help them to make adequate decisions about the patients. Now they could follow the disease much more thoroughly.

\subsection{What knowledge was not transferred, translated or transformed?}

Some physicians have never accepted or used the the Swedish National Rheumatoid Arthritis Register. The reasons for not using the register vary. One explanation is that one populous county council (Region Skåne) has its own quality register and that the registration of patients is very fragmentary in county councils which are not able to employ rheumatologists on a regular basis (e.g Västerbotten). To register patient and treatment data in two quality registers is not considered possible. Neither is it realistic to expect physicians who are not employed on a regular basis to drastically change their normal work routines for some weeks or some months. From the interviews, it was evident that most healthcare workers are willing and motivated to share knowledge, but 
not all: "Perhaps they don't want their patients to be judged by others... Some colleagues do not simply find it very interesting to share knowledge." (rheumatologist). A number of rheumatologists also experience lack of time as a barrier to register use, as consultations are tightly scheduled, and the examination of the patient must be given priority before the registration of data in the register. If the added value of the use of the register is not very clear to the physician, it will not be used when time is scarce. This also stresses the importance of management attributed to understanding and supporting physicians to allocate their time more appropriately. A professional culture depicting the physician as a solitary profession, only including the physician and the patient is as if : "It's just the two of them [the physician and the patient], and others should not bother..." (national healthcare manager). Among the physicians there were also some that had started different research projects based on material from other sources that now became obsolete. In the beginning of the implementation there was some resistance by some of the rheumatologists. This kind of resistance slowed down the pace of the register implementation. However, to overcome this organizational and professional culture is a great challenge for implementers of innovations in healthcare.

\section{Discussion and analysis}

The Swedish Rheumatology Quality Register is regarded as an innovation. The actors speak about the register in terms of novelty and newness. It supports them to get an overview of the disease and works as a handy tool to support discursive practices. However, the register might in the near future become institutionalized. Hence, the novelty in this context underscores the relational nature of what the actors perceive as an innovation and that there is no external vantage point.

The focus on knowledge boundaries has not only been a way to put theoretical inquires into play in an empirical context with the aim to understanding different factors of impact when innovation is desired generally, but finds its relevance in a healthcare sector too that is built upon different specializations of different kinds of knowledge. Our main focus has been on the register and physicians' statements. Many more actors in the healthcare sector are involved in the innovation process and they are at the same time the place for its articulation. We might say, for that reason, that the healthcare sector has great potential to become innovative far beyond the innovation put forward in this case.

It is worth noticing that the register in focus has its own qualities. The objective measurement by localizing pain caused by rheumatoid arthritis is something that might be done either by casting a gaze on the patient or examining her body, and by the patient him/herself. It means that the register cannot be said to work in the same way for other diseases too. Mental illnesses, for example, are quite different to locate compared to swollen knees etc. However, the actors are involved in a process of transferring, negotiating and sharing meanings about the register. With the empirical material at hand, and deduced from the analytical discussion, the following scheme can work as a pragmatic schematic roadmap (to solve the particular problem) when innovation is desired (table 2). It shows both basic conditions for an innovation and different circumstances, challenges and solutions that are of importance. 
Table 2. Approaches of sharing and assessing domain-specific knowledge across boundaries in the innovation of the Swedish National Rheumatoid Arthritis Register.

\begin{tabular}{|c|c|c|c|}
\hline & Syntactic boundary & Semantic boundary & $\begin{array}{l}\text { Pragmatic } \\
\text { boundary }\end{array}$ \\
\hline $\begin{array}{l}\text { Circum- } \\
\text { stances }\end{array}$ & $\begin{array}{l}\text { Knowledge is posited as } \\
\text { "objective", external, } \\
\text { retrieved, explicit, and } \\
\text { capable of being } \\
\text { codified and transferred } \\
\text { across rheumatologists } \\
\text { in different contexts. } \\
\text { A common language } \\
\text { comprising e.g. } \\
\text { measurements of } \\
\text { disease activity, user } \\
\text { interfaces and disease } \\
\text { activity summaries and } \\
\text { other reports from the } \\
\text { register. } \\
\text { The more information, } \\
\text { the better. }\end{array}$ & $\begin{array}{l}\text { Common meanings need } \\
\text { to be developed about the } \\
\text { purposes of using the } \\
\text { register in clinical } \\
\text { practice and research. }\end{array}$ & $\begin{array}{l}\text { Some rheumatologists } \\
\text { are less able and } \\
\text { willing to change their } \\
\text { knowledge to } \\
\text { accommodate the } \\
\text { knowledge developed } \\
\text { by another group. } \\
\text { Rheumatologists } \\
\text { opposing the register as } \\
\text { they both do not want } \\
\text { to be controlled by } \\
\text { authorities, such as } \\
\text { county council } \\
\text { management, or The } \\
\text { National Board of } \\
\text { Health and Welfare, } \\
\text { and that they have } \\
\text { already invested their } \\
\text { knowledge in other } \\
\text { registers. }\end{array}$ \\
\hline Solutions & $\begin{array}{l}\text { Transferring knowledge } \\
\text { through organized user } \\
\text { training offered by the } \\
\text { champion implementer. } \\
\text { Transferring knowledge } \\
\text { to patients through } \\
\text { patient interest groups } \\
\text { and information folders. } \\
\text { The more information } \\
\text { about the register, the } \\
\text { better it is }\end{array}$ & $\begin{array}{l}\text { Supporting } \\
\text { communication across } \\
\text { boundaries. Knowledge } \\
\text { brokering in the } \\
\text { professional community } \\
\text { of rheumatologists. } \\
\text { Creating collective } \\
\text { stories: Encouraging } \\
\text { rheumatologists and } \\
\text { patients to evaluate and } \\
\text { talk about the systems' } \\
\text { advantages and } \\
\text { disadvantages. } \\
\text { Encouraging } \\
\text { rheumatologist to 'try" } \\
\text { the innovation to } \\
\text { experience what added } \\
\text { value could be } \\
\text { accomplished in clinical } \\
\text { practice and research. }\end{array}$ & $\begin{array}{l}\text { Encouraging use of the } \\
\text { register to improve the } \\
\text { health status of patients } \\
\text { instead of control. } \\
\text { Further stressing and } \\
\text { developing the } \\
\text { common interest of } \\
\text { healthier patients given } \\
\text { the right treatment. } \\
\text { Inform all parts in the } \\
\text { healthcare sector about } \\
\text { the value of the system, } \\
\text { both for different } \\
\text { individual actors and } \\
\text { different clinics and } \\
\text { organizations. }\end{array}$ \\
\hline
\end{tabular}




\begin{tabular}{|c|c|c|c|}
\hline & & $\begin{array}{l}\text { Realising that knowledge } \\
\text { to some (large) extent is } \\
\text { tacit, situated and } \\
\text { experimental and not } \\
\text { easily articulated or } \\
\text { codified. } \\
\text { Let the process take time } \\
\text { and unfold naturally. }\end{array}$ & $\begin{array}{l}\text { Making fundamentally } \\
\text { different interest } \\
\text { groups understand that } \\
\text { their goals of increased } \\
\text { health status of patients } \\
\text { are identical. }\end{array}$ \\
\hline Challenges & $\begin{array}{l}\text { Making different } \\
\text { individuals and } \\
\text { specialists integrate } \\
\text { knowledge about the } \\
\text { system by serving as } \\
\text { information channels in } \\
\text { the healthcare sector, } \\
\text { and to share } \\
\text { information. }\end{array}$ & $\begin{array}{l}\text { To coordinate differences } \\
\text { in meaning, assumptions, } \\
\text { and contexts among the } \\
\text { rheumatologists. } \\
\text { Creating shared meanings } \\
\text { about the value of the } \\
\text { register, both on an } \\
\text { individual and } \\
\text { organizational level. } \\
\text { Making physicians accept } \\
\text { "a third person" (the } \\
\text { register) in the } \\
\text { physician - patient } \\
\text { relationship. }\end{array}$ & $\begin{array}{l}\text { To modify some of the } \\
\text { rheumatologists' } \\
\text { existing knowledge } \\
\text { that requires } \\
\text { investment in time and } \\
\text { compromises in valued } \\
\text { community practices } \\
\text { and interest. }\end{array}$ \\
\hline
\end{tabular}

Within a pragmatic approach, it is also necessary to put the register as an instrumental technology into focus. To transfer knowledge about the register means that we know what the register is all about and how it works. To translate knowledge means to share meanings, to emphasize a set of actions or events that embody coherence of unity of purpose. To transform knowledge means to create common interests to share and assess knowledge about the register. These knowledge processes are dependent on the register and how it works. Technology and its relationship to organizational processes have long been of interest to organizational researchers and is a huge research field on its own. In this article we have focused on innovation and boundaries and not on the register as a technology. However, some characteristics about the technology can be found in our empirical material and are relevant to mention. Within a pragmatic approach we might say that to build a register without any flaws might drive the innovation. The trade-off between the number of variables in the register and time spent on data entry might be of importance regarding the challenges and solutions for the innovation presented above. Perceived flaws in interface and reports of the register are all phenomena that could be linked to the register and hinder its dissemination. However, these instrumental characteristics about the system are all implicitly included in the syntactic, semantic, and pragmatic boundaries in the roadmap. 
However, the schematic roadmap should be followed with caution. The empirical material shows indeed the necessity to take context-specific aspects into consideration and social contractions like technocratic control, normative rules, institutional settings, the actors' capacities or suchlike explanatory factors of how actors enact innovation are important factors in this context, too. Another limitation of our study is the general focus on physicians' interaction with the register. Many more professional groups are involved in making this innovation successful. Administrators and nurses, for example, help patients to use the system adequately.

We are well aware that the empirical framework only works for illustrative purposes, with the purpose to clarify and gain a better understanding. Nevertheless the framework (cf. analytical generalization) can help us pinpoint boundaries that are put into play in different innovation processes. The framework could also be extended to fit into a broader context. A robust theory can be enacted in many different contexts and often related to many different empirical arenas. Carlile's framework could be said to be one example of a robust theory and might be applied to different empirical arenas in the healthcare sector when innovation is desired. We do not lack empirical arenas waiting to be analyzed, discussed and managed. For example; even if healthcare might be said to be rich in evidence-based innovations, yet even when such innovations are implemented successfully in one location, it may disseminate slowly - if at all in other locations (cf. Berwick, 2002).

However, still new innovations in the healthcare sector will occur when actors involved do have sufficient capacity and ability to navigate to maintain an innovative climate. Even if the innovation we focus on might be institutionalized in the near future there is much more going on under the surface.

\section{Concluding remarks - Challenges ahead}

What we also can notice is that new practices and new outcomes will follow the further implementation of the system. We can especially discern two outcomes with both theoretical and practical implications. The first implication is more fundamental. Evidence-based medical guidelines are the role-model for the investigation and treatment in healthcare. The register can be seen as a tool to further refine such guidelines. In line with the epistemic foundations of modernity these guidelines rely on an understanding of written, universal, general and timeless laws (cf. Toulmin, 1990). It is an abstract and generalized conception of knowledge to be applied to many different processes. But, the physicians do also practice practical reasons, which manifest as clinical judgment. To explore the relationship between guidelines and practical reason is far beyond the scope of this article. However, our empirical material shows how physicians and patients do appreciate how the patient can become more involved in the treatment by being better prepared and becoming more involved in the discussion with the physician, supported by non-discursive practices (i.e. examination). This kind of practical activity can gain further depths of meaning of the whole treatment process. It reminds us that the register, instead of being a container-like tool where knowledge is imagined to reside as a kind of stable entity or stock of fixed information, it becomes a complex system of discursive and nondiscursive practices (cf. Giddens, 1984; Hutchin, 1993; Bourdieu, 1977). It also makes clear that knowledge is structured by the problems and possibilities faced within these practices. Practically, that might mean that the register propels a simultaneous practice of evidence-based medical guidelines and local embedded and embodied knowledge, 
knowledge processes that might change the relationship between the physician and the patient, the healthcare process as well as the healthcare sector.

The second implication is also fundamental, but for different reasons. The patients have, for different reasons, become much more involved in the healthcare process. They can use the register to "see" and understand more of the workflow. The register helps them see how their problems and their diseases become part of a whole healthcare process. For that reason we might regard the register in terms of a whole innovation system where partly traditional hierarchical organizations and processes have become obsolete. In the near future, the register may become part of a wider process of virtualization of working processes in line with what can be seen as a fundamental phenomenon in the ICT society (see for example Zammuto et al., 2007). What we can notice from our empirical material is how innovation processes in general are dispersed and opened up. The champion implementer does already plan to open up the register for the patients too. Notwithstanding a lot of ethical issues waiting to be solved, would be qualitative step to a partly new healthcare innovation system, with new questions to be asked and a partly new healthcare sector to shed light on.

\section{Acknowledgements}

The study was part of the research project Chronic Health, financed by the Swedish Vinnvård Foundation. The authors wish to thank the anonymous reviewers of the journal, the respondents of the study and language reviewer Carol-Ann Soames, Jönköping International Business School.

\section{References}

1 Barley, S. R. \& Kunda, G. (2004). Gurus, hired guns and warm bodies: Itinerant experts in a knowledge economy. New Jersey, NY: Princeton University Press.

2 Berwick, D. M. (2002). Public performance reports and the will for change. Journal of the American Medical Association, 288(12), 1523-1524.

3 Berwick, D. M. (2003). Disseminating innovations in health care. Journal of the American Medical Association, 289(15). 1969-1975.

4 Boland, R. J. \& Tenkasi, R. V. (1995). Perspective making and perspective taking in communities of knowing. Organization Science, 5(4), 350-372.

5 Bourdieu, P. (1977). Outline of a theory of practice. Cambridge: Cambridge University Press.

6 Bosa, I. (2008). Innovative doctors in Germany: Changes through communities of practice. Journal of Health, Organization and Management, 22(5), 465-479.

7 Brown, J. \& Eisenhardt, K. (1997). The art of continuous change: Linking complexity theory and time-paced evolution in relentlessly shifting organizations. Administrative Science Quarterly, 42(1), 1-34. 
8 Brown, J. \& Duguid P. (1998). Organizing knowledge. California Management Review, 40(3), 90-111.

9 Carlile, P. R. (2002). A pragmatic view of knowledge and boundaries: Knowledge and boundary activities on technology development teams. Working paper. Cambridge, MA: Sloan, MIT.

10 Carlile, P.R. (2004). Transferring, translating, and transforming: An integrative framework for managing knowledge across boundaries. Organization Science, 15(5), 555-568.

11 Constas, M. A. (1992). Qualitative analysis as a public event: The documentation of category development procedures. American Educational Research Journal, 29(2), 253-266.

12 Fitzgerald, L., Ferlie, E., Wood, M. \& Hawkins, C. (2002). Interlocking interactions, the diffusion of innovations in health care. Human relations, 55(12), 1429-1449.

13 Garpenby, P. \& Carlsson, P. (1994). The role of national quality registers in the Swedish health service. Health Policy, 29(3), 183-195.

14 Giddens, A. (1984). The constitution of society: Outline of the theory of structuration. Cambridge: Polity Press.

15 Gremler, D. D. (2004). The critical incidents technique in service research. Journal of Service Research, 7(11), 65-89.

16 Gupta, A., Tesuk, P. \& Taylor, S. (2007). Innovation at and across: Multiple levels of analysis. Organization Science, 18(6), 885-897.

17 Hanson, N. R. (1958). Patterns of discovery: An inquiry into the conceptual foundations of science. Cambridge: Cambridge University Press.

18 Hutchin, E. (1993). Learning to navigate: the contributing process and literatures. In Cohen, M. \& Sproull, S. (Eds.), Organizational Learning. Thousand Oaks, CA: Sage publications.

19 Jacobs, K., Marcon, G. \& Witt, D. (2004). Cost and performance information for doctors: An international comparison. Management Accounting Research, 15(3), 337-54.

20 Jong, J. \& Hartog, D. (2007). How leaders influence employee's innovative behavior. European Journal of Innovation Management, 10(1), 41-62.

21 Keller, C., Gäre, K., Edenius, M. \& Lindblad, S. (2009). Designing for complex innovations in healthcare: Design theory and realist evaluation combined, Proceedings of DESRIST the 4th International Conference on Design Science Research in Information Systems and Technology 2009, in Malvern, PA. 
22 Kellogg, K., Orlikowski, W. \& Yates, J. (2006). Life in the trading zone: Structuring coordination across boundaries in post bureaucratic organizations. Organization Science, 17(1), 22-44.

23 King, N. \& Anderson, N. (2002). Managing innovation and change: A critical guide for organizations. London: Thomson Learning.

24 Lave, J. \& Wenger, E. (1991). Situated learning. Cambridge: Cambridge University Press.

25 Leonard-Barton, D. (1995). Well springs of knowledge: Building and sustaining the source of innovation. Boston, MA: Harvard Business School Press.

26 McAdam, R. \& McClelland, J. (2002). Individual and team-based idea generation within innovation management: organizational and research agendas. European Journal of Innovation Management, 5(2), 86-97.

27 Montgomery, K. (2006). How doctors think: Clinical judgment and the practice of medicine. Oxford: Oxford University Press.

28 Mumford, M. F. (2000). Managing creativity people: strategies and tactics for innovations. Human Resources Management Review, 10(3), 313-351.

29 Orlikowski, W. (1992). The duality of technology: Rethinking the concept of technology in organizations. Organization Science, 3(3), 398-427.

30 Orlikowski, W. (2000). Using technology and constituting structures: A practice lens for studying technology in organizations. Organization Science, 11(4), 404-428.

31 Research on Innovation (2010). Research on innovation. http://www.researchoninnovation.org/. Retrieved 2010-02-10.

32 Rogers, E. M. (2003). Diffusion of innovations. $5^{\text {th }}$ edition. New York: The Free Press.

33 Simon, H. A. (1982). Models of bounded rationality: Empirically grounded economic reason. Cambridge, MA: MIT Press.

34 Smirch, L. (1983). Concepts of culture and organizational analysis. Administrative Science Quarterly, 28(3), 339-358.

35 Spradley, J. P. (1979). The ethnographic interview. New York: Holt.

36 Stake, R. E. (1995). The art of case study research. Thousand Oaks, CA: Sage Publications.

37 Swedish Association for Local Authorities and Regions. (2007). National healthcare quality registries in Sweden. Stockholm: Swedish Association for Local Authorities and Regions. 
38 Sveriges Kommuner och Landsting (SKL) [Swedish Association for Local Authorities and Regions]. (2009). Nationella kvalitetsregister inom hälso- och sjukvården [National healthcare quality registers]. Stockholm: Sveriges Kommuner och Landsting [Swedish Association for Local Authorities and Regions].

39 Taylor, S. J. \& Bogdan, R. (1998). Introduction to qualitative research methods: A guidebook and resource. $3^{\text {rd }}$ edition. New York: John Wiley \& Sons.

40 Teece, D., Pisano, G. \& Shuen, A. (1997). Dynamic capabilities and strategic management. Strategic Management Journal, 18(7), 509-533.

41 Thorne, M. (2002). Colonizing the new world of NHS management: The shifting power of professionals. Health Service Management Research, 15(1), 14-26.

42 Toulmin, S. (1990). Cosmopolis - the hidden agenda of modernity. New York: The Free Press.

43 Tsoukas, H. (1989). The validity of ideographic research explanations. Academy of Management Review, 14(4), 551-561.

44 Tushman, M. \& O'really, A. (1997). Winning through innovation: A practical guide to leading organizational change and renewal. Boston, MA: Harvard Business School Press.

45 van de Ven, A. (1986). Central problems in the management of innovation. Management Science, 32(5), 590-607.

46 Verona, G., Priandelli, E. \& Sahwney, M. (2006). Innovation and virtual environments: Towards virtual knowledge brokers. Organization Studies, 27(6), 765-788.

47 Yin, R.K. (2009). Case study research: design and methods. $4^{\text {th }}$ edition. Thousand Oaks, CA: Sage Publications.

48 Zaltman, G., Duncan, R. \& Holbek, J. (1973). Innovations and organizations. New York: John Wiley and Sons.

49 Zammuto, B., Griffith, T., Majchrzak, A., Dougerty, D. \& Faraj, S. (2007). Information technology and changing the fabric of organization. Organization Science, 18(5), 749-762. 